\title{
Futbolcularda Yo-Yo Aralıkıı Toparlanma Testlerindeki (Seviye 1-2) Kalp Atım Hızı, Laktat Profili ve Toparlanma Sürelerinin İncelenmesi
}

The Examination of Heart Rate, Lactat Profile, and Recovery Times in Yo-Yo Interval Recovery Tests (Level 1-2) in Football Players

\author{
Serdar BAYRAKDAROĞLU ${ }^{1}$, İbrahim CAN²$^{2}$, Ahmet Yılmaz ALBAYRAK ${ }^{3}$, Recep IMAMOĞLU ${ }^{4}$
}

\section{ÖZ}

$\mathrm{Bu}$ çalışmanın amacı; futbolcularda Yo-Yo aralıklı toparlanma testlerindeki (seviye 1-2) maksimal kalp atım hızı $\left(\mathrm{KAH}_{\text {maks }}\right)$, laktat profili ve toparlanma sürelerinin incelenmesidir. Bu amaçla, 13 amatör genç futbol oyuncusu (yaş: $18,9 \pm 1,38$ yıl; boy uzunluğu: $176,1 \pm 7,11 \mathrm{~cm}$; vücut ağırlığg: $67,5 \pm 6,78 \mathrm{~kg}$ ) çalışmaya gönüllü olarak katıldı. Çalışmada katılımcılara boy/kilo, Yo-Yo aralıklı toparlanma seviye 1 ve seviye 2 (Yo-Yo AT1 ve Yo-Yo AT2) testleri uygulandı. Yo-Yo aralıklı toparlanma testlerinde, kalp atım hızı $(\mathrm{KAH})$, laktat değeri ve toparlanma süresi parametreleri belirlendi. Yo-Yo AT1 ve Yo-Yo AT2 testlerinin parametreleri arasındaki farklılık ilişkili örneklemler için T-testi ile, ilişki ise Pearson Korelasyon katsayısıyla incelendi. Analiz sonuçlarına göre, maksimal kalp atım hızı parametresi bakımından Yo-Yo AT1 (188,1 $\pm 1,86$ atım/dk) ve Yo-Yo AT2 (191,0 $\pm 3,09$ atım/dk) testleri arasında istatistiksel olarak anlamlı bir farklılık olduğu belirlendi $\mathrm{p}<0.05)$. Buna karşılık, Yo-Yo AT1 ve YoYo AT2 testlerinin ön-test $(1,91 \pm, 53 \mathrm{mmol} / \mathrm{L}$ ve $2,00 \pm, 40 \mathrm{mmol} / \mathrm{L}$, siraya göre) son-test laktat değerleri $(14,9 \pm, 72 \mathrm{mmol} / \mathrm{L}$ ve $15,7 \pm 1,10 \mathrm{mmol} / \mathrm{L}$, siraya göre) arasında istatistiksel olarak anlamlı bir farklılık

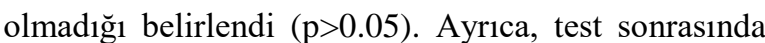
KAH değerinin normale dönüş süresinin Yo-Yo AT2 testinde daha yavaş olduğu görüldü. Sonuç olarak, Yo-Yo AT2 testinde kat edilen mesafenin daha düşük olmasına rağmen, koşu hızının yüksek olmasından dolayı fizyolojik yanıtların daha yüksek olduğu söylenebilir.

Anahtar Kelimeler: Test, Kalp atım hız1, Laktat, Toparlanma

\begin{abstract}
The purpose of this study is to analyze maximum heart rate $\left(\mathrm{HR}_{\max }\right)$, lactate profile and recovery durations in Yo-Yo interval tests (level 1 and 2) of football players. In line with this objective, 13 young football players playing in 1st amateur division (age: 18,9 $\pm 1,38$; height: $176,1 \pm 7,11$; weight: $67,5 \pm 6,78$ ) participated voluntarily in research. In study participants were conducted weight/height measurements and Yo-yo interval recovery tests level 1-2. Heart rate (HR), lactate values and recovery duration parameters were determined in Yo-yo interval recovery tests. The difference between two test parameters was analyzed with T-test for those that are relevant, and the relation between the parameters was analyzed through Pearson Correlation test. According to analysis results, It was determined that there was a statistically significant difference $(\mathrm{p}<0.05)$ between YO-Yo AT1 $(188,1 \pm 1,86 \mathrm{rate} / \mathrm{min})$ and YoYo AT2 (191,0 $\pm 3,09 \mathrm{rate} / \mathrm{min})$. On the other hand, there was no statistically significant difference ( $p>0.05)$ between pretest $(1,91 \pm, 53 \mathrm{mmol} / \mathrm{L}$ ve

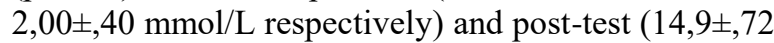
$\mathrm{mmol} / \mathrm{L}$ ve $15,7 \pm 1,10 \mathrm{mmol} / \mathrm{L}$ respectively) lactate values in Yo-Yo AT1 and Yo-Yo AT2 tests. Furthermore, returning duration to normal level of heart rate right after the test were seen to be slower in Yo-Yo AT2 test. In conclusion, despite the participants covered a lower running distance in YoYo AT2 test, they gave higher physiological responses as the running speed was higher.
\end{abstract}

Keywords: Test, Heart rate, Lactate, Recovery

Bu çalışma 16.A0311.02.01 proje no ile Gümüşhane Üniversitesi Bilimsel Araştırma Projeleri tarafindan desteklenmiştir (09.08.201612.12.2017).Çalışma için Karadeniz Teknik Üniversitesi, Tıp Fakültesi Bilimsel Araştırmalar Etik Kurul Başkanlı̆̆ı'ndan etik izin (Tarih: 03.08.2016, Sayl: 24237859-478, No: 2016/54) alınmıştır.

${ }^{1}$ Dr. Öğr. Üyesi, Serdar BAYRAKDAROĞLU, Hareket ve Antrenman, Gümüşhane Üniversitesi Beden Eğitimi ve Spor Yüksekokulu Antrenörlük Eğitimi Bölümü, bayrakdaroglu85@gmail.com, ORCID: 0000-0002-2166-6675

2 Doç. Dr., İbrahim CAN, Hareket ve Antrenman, Iğdır Üniversitesi Beden Eğitimi ve Spor Yüksekokulu, Antrenörlük Eğitimi Bölümü, ibrahimcan_61_@hotmail.com, ORCID: 0000-0002-2050-1473

${ }^{3}$ Dr. Öğr. Üyesi, Ahmet Yılmaz ALBAYRAK, Spor Yönetimi, Gümüşhane Üniversitesi Beden Eğitimi ve Spor Yüksekokulu Spor Yöneticiliği Bölümü, ahmetyilmazalbayrak@hotmail.com, ORCID: 0000-0002-3345-6579

4 Öğr. Gör., Recep İMAMOĞLU, Hareket ve Antrenman, Gümüşhane Üniversitesi Rektörlük Birimi Beden Eğitimi Bölümü, recepimamoglu@gmail.com, ORCID: 0000-0003-3995-9465 


\section{GİRIȘ}

Futbol; dünyada oldukça popüler olan ve oyuncuların başarılı olabilmesi için teknik taktik becerilerinin yanı sıra, ${ }^{1}$ hem aerobik hem de anaerobik uygunluğun çok iyi geliştirilmesini gerektiren yüksek yoğunlukta yapılan aralıklı bir fiziksel aktivitedir. ${ }^{2}$ Yüksek standartlarda rekabet için oyuncuların oyunun gerekliliklerine uyum sağlaması gerekir. ${ }^{3}$ Birçok profesyonel futbol oyuncusu için her yıl 8 ila 10 aylık bir dönem müsabaka sezonudur. Eğer oyuncular ulusal ve uluslararası turnuvalara katılan üst düzey ulusal kulüplerde mücadele ediyorsa, her yıl ortalama 60 maç oynayabilirler. ${ }^{4}$ Futbol her 3-5 saniyede değișen aktivite aralıkları ile yapılır ve kuvvet çalışmaları, sprintler, yüksek hızda koşular, dönmeler ve sıçramalar gibi hareket aktiviteleri içeren bir spor dalı olarak kabul edilir. Kalp atım hızı $(\mathrm{KAH})$ ve kan örnekleri üzerine yapilan incelemelerde, futbol maçlarının genelinde aerobik yükün, maç periyotları esnasında anaerobik enerji kaybının çok yüksek olduğu belirlenmiştir. ${ }^{5}$ Yürüme ve düşük şiddetli koşular gibi aerobik egzersizler, futbolda sıklıkla uygulanmaktadır. ${ }^{6}$

Bir futbol müsabakasında, oyunun şiddetine göre futbolcuların sprint atması, top kapma mücadelesine girmesi, tempolu ve dönüşlü koşular yapması gerekir. Yoğunluğun arttığ 1 bu gibi durumlarda anaerobik metabolizma, yoğunluğunun submaksimal seviye altında olduğu durumlarda aerobik metabolizma etkindir. 90 dakikalık bir futbol maçında ortalama egzersiz yoğunluğu maksimal kalp hızının \% 80-90'1 ya da anaerobik laktat eșiği civarındadır. $^{7-8}$ Futbol müsabakaları, yüksek laktat birikimine sebep olan şiddetli aktivitelerden oluşmaktadır. ${ }^{1}$ Yüksek laktat birikiminden dolayı, şiddetli egzersizlerin uzun süre sürdürülebilmesi imkansızdır. $\mathrm{Bu}$ nedenle, oyuncular kanda biriken laktat1 uzaklaştırmak için düşük yoğunluktaki aktivite periyotlarına ihtiyaç duymaktadır. ${ }^{9}$

Müsabakanın süresinden dolayı enerji salınımı aerobik yollardan sağlanır. Enerji temini yaklaşık \% 90 oranında aerobiktir ve bu nedenle mücadeleye dayalı futbol oyununda yaygin metabolik yol aerobik enerjidir. ${ }^{3}$ Futbol oyuncuları, müsabakanın yüksek şiddetli periyotlarında fizyolojik yüke dayanmak için aerobik kapasitesini geliştirmelidir. ${ }^{10}$ Yüksek bir aerobik uygunluk, futbol performansı veya antrenmanı esnasında yüksek yoğunluktaki aralıklı egzersiz anında toparlanmaya katkı sağlar. ${ }^{11}$ Sporcuların egzersiz ve müsabaka sonras1 toparlanma süreleri performans1 etkileyen önemli faktörlerden biridir. $\mathrm{Bu}$ sürenin kısa olması bir sonraki antrenman ve müsabaka için optimal performans sergilenebilmesi açısından sporculara avantaj sağlar. ${ }^{12}$

Futbolda oyuncuların dayanıklılık durumlarını belirleyip değerlendirmek için tasarlanmış birçok laboratuvar ve saha testleri vardır. $\mathrm{Bu}$ testlerin tasarlanmasıyla son yillarda futbol branşında performans ve yeni antrenman yöntemleri alanlarında birçok araştırmanın yapılmasını sağlamıştır. ${ }^{13}$

Yo-Yo aralıklı toparlanma testleri (Yo-Yo AT), bireysel veya takım sporlarındaki sporcuların aerobik performansını belirlemek için mekik koşusu testinden yola çıkılarak Bangsbo $^{7}$ tarafından geliştirildi. Testin en önemli avantajları; kalabalı sporcu gruplarında uygulanabilmesi, uygulanışının kolay olmasi, sporcularin kendi spor branşlarının karakteristiğini yansıtan doğal ortamlarda test edilebilmesini sağlamas1, geçerlilik ve güvenilirliğinin yüksek olmasıdır. ${ }^{14}$ Yo-Yo AT testlerinin seviye 1 (Yo-Yo AT1) ve seviye 2 (Yo-Yo AT2) olmak üzere iki farklı seviyesi vardır. Yo-Yo AT1 testi, daha düşük bir koşu hızında (10 $\mathrm{km} / \mathrm{h}$ ) başlar ve antrenmanlı sporcularda 10 ila 20 dakika arasında sonlanır. Buna karşılık, Yo-Yo AT2 testinin başlangıç hızı daha yüksektir $(13 \mathrm{~km} / \mathrm{h})$ ve 5 ila 15 dakika arasında sonlanır. ${ }^{15}$ Her iki Yo-Yo testinde de sporcuların toparlanmalarını sağlamak için 10 saniyelik kısa bir dinlenme süresi vardır. Futbol gibi aralıklı olarak ifade edilen spor branşlarında, sporcular kısa toparlanma dönemleri ile yüksek yoğunluklu aktiviteleri tekrarlayarak yapmaktadırlar. $\mathrm{Bu}$ nedenle, 
k1sa toparlanma dönemlerine sahip olan YoYo aralıkl toparlanma testleri, k1sa toparlanma döneminden sonra şiddetli bir egzersizi yapabilme yeteneğinin özellikle müsabaka sonucu için önemli olduğu aralıklı sporlar için oldukça uygundur. ${ }^{16,17}$ Bundan dolayı testler, aralıklı sporlardaki oyuncuların dayanıklılık kapasitesini ölçmek için yaygın olarak kullanılır. AT1 testi bir müsabakada yapılan yüksek yoğunlukta aktivite miktarı ile $^{18}$; AT2 testi ise 5 dakikalık bir periyotta yüksek yoğunluktaki en yüksek koşu mesafesi ile ilişkilidir. ${ }^{5}$

Futbol hem aerobik hem de anaerobik sistemlerin yaygın olarak kullanıldığı, maçlar esnasında pozitif ve negatif ivmelenme periyotlarını içermesinden dolayı aralıklı bir spor olarak tanımlanır. Aynı şekilde, Yo-Yo AT testleri de pozitif ve negatif ivmelenme ve kısa toparlanma periyotlarını içerdiği için aralıklı test olarak kabul edilir ve sporcuların aerobik performansını belirlemek için antrenörler ve spor bilimciler tarafindan sıklıkla kullanılır. Yo-Yo aralıklı toparlanma testlerindeki performans ile aerobik özellik izlenebilir. ${ }^{19} \mathrm{Bu}$ nedenle, futbolda başarılı bir performans için önemli bir parametre olduğu kabul edilen aerobik özellik için oyuncuların Yo-Yo AT1 ve Yo-Yo AT2 testlerine verdiği fizyolojik yanitların incelenmesi gerekir. $\mathrm{Bu}$ çalışmada bir futbol müsabakasında önemli bir etken olan aerobik uygunluğun belirlenmesi için uygulanan Yo-Yo AT1 ve Yo-Yo AT2 testlerinde kalp atım hızı, laktat profili ve toparlanma süreleri gibi fizyolojik yanıtların karşılaştırılması amaçlanmıştır.

\section{MATERYAL VE METOT}

\section{Araştırmanın Türü}

$\mathrm{Bu}$ çalışmada nicel araştırma yöntemlerinden deneysel desen metodu kullanılmıştır.

\section{Araştırmanın Evren ve Örneklemi}

$\mathrm{Bu}$ araştırmanın evrenini, Gümüşhane ilindeki amatör genç futbol oyuncuları oluştururken, örneklemini ise Gümüşhane ilinde amatör olarak futbol oynayan ve çalışmaya gönüllü olarak katılan 13 genç futbol oyuncusu (yaş: 18,9 $\pm 1,38$ y1l, boy uzunluğu: $176,1 \pm 7,11 \mathrm{~cm}$, vücut ağırlığ̀: $67,5 \pm 6,78 \mathrm{~kg}$ ) oluşturmuştur.

Çalışmaya alt ve üst ekstremitesinde herhangi bir rahatsızlığı olmayan, kardiyovasküler olarak yapılacak testlere uyumlu olan, herhangi bir cerrahi işlem geçirmemiş olan bireyler dahil edildi.

\section{Verilerin Toplanması}

Veri toplama sürecinde ilk olarak antropometrik ölçümler (boy uzunlukları ve vücut ağırlıkları) alındı. Daha sonra 2 aşama olarak Yo-Yo testleri uygulandi. İki Yo-Yo testi arasında sporculara üç (3) günlük bir dinlenme süresi verildi. İlk aşamada, oyunculara Yo-Yo aralıklı toparlanma seviye
1 (Yo-Yo AT1) testi, ikinci aşamada ise YoYo aralıklı toparlanma seviye 2 (Yo-Yo AT2) testi uyguland ve oyuncuların her iki Yo-Yo AT testleri esnasindaki KAH, laktat değerleri ve toparlanma süreleri belirlendi. Kat1limcilara testler öncesinde ve sonrasındaki yakın bir süre içerisinde herhangi bir fiziksel aktiviteye katılmamaları için uyarılar yapıldı.

\section{Veri Toplama Araçları}

\section{Boy ve Vücut Ă̆grlı̆̆ı Ölçümü̈}

Boy uzunluğu ve vücut ağırlığı ölçümleri, Seca 769 marka elektronik ölçüm aleti (Seca Anonim Şirketi, Hamburg, Almanya) kullanılarak elde edildi. Cihaz, boy uzunluğunu $0.1 \mathrm{~cm}$., vücut ağırlığını $0.01 \mathrm{~kg}$. hassasiyetle ölçmektedir. Vücut ağırlığı, katılımcıların ağırlığını etkilemeyecek bir şekilde ayakkabısız ve üstlerinde şort ve tişort ile kilogram $(\mathrm{kg})$ cinsinden ölçüldü. Boy uzunluğu ise ayakkabısız, vücut ağırlığı iki ayağa eşit dağılmış şekilde santimetre $(\mathrm{cm})$ cinsinden ölçüldü.

\section{Yo-Yo Aralıklı Toparlanma Testi}

Katılımcılara Yo-Yo aralıklı toparlanma seviye 1 (Yo-Yo AT1) ve seviye 2 (Yo-Yo 
AT2) testleri uyguland1. Her iki Yo-Yo aralıkl1 toparlanma testinde de oyunculara kademeli artan hızlarda 2 × 20 m'lik mekik koşuları yaptırıldı ve koşu alanını belirlemek için huniler kullanıldı. Her bir koşu alanı için başlangıç çizgisinin 5 metre gerisine konulan ve oyuncuların toparlanma bölgesini gösteren farklı bir huni konuldu. 40 metrelik her bir koşu sonunda sporcular bu aktif toparlanma bölgesinde 10 sn boyunca yürür, jog atar veya durağan kalır. Toparlanma süresi bitmeden, oyuncular tekrar başlangıç çizgisine geldiler ve sinyal sesiyle birlikte bir sonraki koşuya başladılar. Oyuncular bitiş çizgisine zamanında ulaşmada iki kez başarısız olduğunda veya kendi istekleri ile testi bıraktıklarında test sonlandırıldı. ${ }^{15}$ Koşu hızları CD'den işitsel olarak yayılan sinyal sesleri ile belirlendi. Sporculardan daha üst bir koşu performansı alabilmek için test esnasında sözel olarak motive edildiler.

\section{Laktat Ölçümü}

Katılımciların Yo-Yo AT1 ve Yo-Yo AT2 testlerindeki hem test öncesinde hem de test sonundaki kan laktat değerleri lektrokimyasal laktat oksidaz biyosensörü kullanılarak (Lactate Plus, Nova Biomedical USA) ölçüldü. Test öncesindeki ve sonrasındaki laktat değerini ölçmek için öncelikle kan numunesi alınacak-parmak ucu alkol ile silindi ve pamuklu yün ile kurutuldu. Sonra, katılımcının parmak ucu lanset kullanılarak delindi ve hafifce sikıld1. Parmak ucundan çıkan ilk kan silindi ve sonra katılımcının parmak ucu tekrardan sıkılarak çıkan kan tek kullanımlı strip ile elde edildi ve oyuncuların test öncesi ve sonrası kan laktat değerleri belirlendi. Sonuçlar mmol/L olarak gösterildi.

\section{Kalp Atım Hizlart ve Toparlanma Sürelerinin Ölçümü}

Katılımciların Yo-Yo AT1 ve Yo-Yo AT2 testlerindeki kalp atım hızları (KAH) ve test sonrasi-toparlanma süreleri, telemetrik kalp atım monitörü (PolarM400, Finlandiya) ile belirlendi. Her iki test sonundaki $\mathrm{KAH}_{\text {maks }}$ değerleri belirlendi. Testlerin sonunda oyuncular pasif olarak yere oturtularak 0,1 , 3, 5, 7 ve 9. dakikalardaki toparlanma KAH değerleri ölçüldü.

\section{Araştırmanın Etik Yönü}

Araştırmanın gerçekleştirilebilmesi için Karadeniz Teknik Üniversitesi Tip Fakültesi Klinik Araştırmalar Etik Kurul Başkanlığı'ndan 03.08.2016 tarihli 24237859- 478 nolu say1 ve 54 numaralı belge ile gerekli etik kurul izni alındı ve çalışma Helsinki Dekrelasyonuna uygun olarak hazırlandı. Çalışma hakkında oyunculara gerekli bilgilendirmeler yapıldı. Testlerden önceki 3 günlük zaman periyodu içerisinde yüksek şiddetli egzersizden kaçınmaları ve beslenme düzenine dikkat etmeleri gerektiği oyunculara bildirildi. Oyuncular çalışmaya ilişkin gönüllü bilgilendirilmiş onam formunu doldurdular ve çalışmaya gönüllü olarak katılmışlardır.

\section{Verilerin Analizi}

Katılımciların antropometrik, fizyolojik ve performans parametreleri tanımlayıc1 istatistik analiz yöntemi kullanılarak, ortalama, standart sapma, minimum ve maksimum değerler olarak sunuldu. Verilerin normal dağılımını incelemek için ShapiroWilk testi uyguland1. Yo-Yo AT1 ve AT2 testlerinin parametreleri arasındaki farklilık ilişkili örneklemler için T-testi (paired sample T-test) ile, ilişki ise Pearson Korelasyon katsayısıyla incelendi. Tüm istatistiksel analizlerde anlamlılık düzeyi $\mathrm{p}<0.05$ olarak kabul edildi.

\section{Araştırmanın Sınırlılıkları}

Araştırmaya dahil olan katılımcı sayısının az olması (13 amatör futbolcu ile sinırlı), ölçümlere sadece amatör futbol oyuncuların dahil edilmesi ve yeterli sayida ölçüm cihazının olmaması, bu çalışmanın sinırlılıklarıdır. 


\section{BULGULAR VE TARTIŞMA}

Yapılan analizler sonucunda katılımciların Yo-Yo AT testleri (seviye 1 ve 2) sonundaki toparlanma değerleri tablo 1'de, Yo-Yo AT testlerinde katedilen koşu mesafesi ve testlere verdikleri fizyolojik yanitlar tablo 2'de, testler esnasında ulaşılan fizyolojik yanıtların karşılaştırılması tablo 3'de ve Yo-Yo AT testleri arasındaki ilişki tablo 4'de verilmiştir.

Tablo 1. Katılımcıların Yo-yo Aralıkı Toparlanma Testleri Sonundaki Toparlanma Değerleri

\begin{tabular}{|c|c|c|c|c|c|c|c|}
\hline \multirow{2}{*}{$\begin{array}{l}\text { Toparlanma } \\
\text { Süreleri }\end{array}$} & \multirow{2}{*}{$\mathbf{n}$} & \multicolumn{3}{|c|}{ Yo-Yo AT1 } & \multicolumn{3}{|c|}{ Yo-Yo AT2 } \\
\hline & & Minimum & Maksimum & Ortalama \pm SS & Minimum & Maksimum & Ortalama \pm SS \\
\hline 0 Dakika (atım/dk) & 13 & 185,0 & 192,0 & $188,1 \pm 1,86$ & 188,0 & 198,0 & $191,1 \pm 3,02$ \\
\hline 1 Dakika (atım/dk) & 13 & 135,0 & 152,0 & $145,4 \pm 4,44$ & 141,0 & 164,0 & $147,7 \pm 6,30$ \\
\hline 3 Dakika (atım/dk) & 13 & 111,0 & 135,0 & $123,7 \pm 5,84$ & 120,0 & 141,0 & $130,7 \pm 8,10$ \\
\hline 5 Dakika (atım/dk) & 13 & 110,0 & 130,0 & $116,3 \pm 4,99$ & 109,0 & 128,0 & $118,5 \pm 5,88$ \\
\hline 7 Dakika (atım/dk) & 13 & 104,0 & 123,0 & $111,9 \pm 5,52$ & 105,0 & 115,0 & $110,6 \pm 3,03$ \\
\hline 9 Dakika (atım/dk) & 13 & 106,0 & 116,0 & $106,6 \pm 1,98$ & 104,0 & 114,0 & $107,0 \pm 2,58$ \\
\hline
\end{tabular}

Tablo 1 incelendiğinde, katılımcıların YoYo AT1 testi tamamlandiktan sonra ortalama KAH değerlerinin 188,1 $( \pm 1,86 \mathrm{at}$ tm/dk $), 1$ dakika sonra 145,4 ( \pm 4,44 atım/dk), 3 dakika sonra 123,7 ( $\pm 5,84 \mathrm{atım} / \mathrm{dk}), 5$ dakika sonra $116,3( \pm 4,99$ at1m/dk), 7 dakika sonra 111,9 $( \pm 5,52 \mathrm{at} 1 \mathrm{~m} / \mathrm{dk})$ ve 9 dakika sonra 106,6 ( \pm 19,98 atım/dk) olduğu görülmektedir. Yo-Yo AT2 testinden sonra ortalama KAH değerleri 191,1 ( $\pm 3,02 \mathrm{at}$ mm/dk), 1 dakika sonra 147,7 $( \pm 6,30 \mathrm{at} 1 \mathrm{~m} / \mathrm{dk}), 3$ dakika sonra 130,7 $( \pm 8,10$ atım/dk), 5 dakika sonra 118,5 $( \pm 5,88$ atım/ $\mathrm{dk}), 7$ dakika sonra 110,6 ( $\pm 3,03 \mathrm{at} 1 \mathrm{~m} / \mathrm{dk})$ ve
9 dakika sonra 107,0 ( $\pm 2,58$ atım/dk) olduğu görülmektedir. Her iki Yo-Yo AT testinde de katılımcıların KAH değerlerinin kademeli bir şekilde azaldığı görülmektedir.

Tablo 2. Katılımcıların Yo-Yo Aralıkı Toparlanma Testlerindeki Koşu Mesafeleri ve Testlere Verdikleri Fizyolojik Yanitlar

\begin{tabular}{|c|c|c|c|c|c|c|c|}
\hline \multirow{2}{*}{ Değişkenler } & \multirow{2}{*}{$\mathbf{n}$} & \multicolumn{3}{|c|}{ Yo-Yo AT1 } & \multicolumn{3}{|c|}{ Yo-Yo AT2 } \\
\hline & & Minimum & Maksimum & $\begin{array}{c}\text { Ortalama } \pm \\
\text { SS } \\
\end{array}$ & Minimum & Maksimum & $\begin{array}{c}\text { Ortalama } \pm S \\
\mathbf{S} \\
\end{array}$ \\
\hline Koşu Mesafesi(m) & 13 & 960,0 & 2320,0 & $1529,2 \pm 331,5$ & 440,0 & 1080,0 & $738,4 \pm 154,5$ \\
\hline $\begin{array}{l}\text { Laktat Ön Test } \\
(\mathrm{mmol} / \mathrm{L})\end{array}$ & 13 & 1,10 & 2,80 & $1,91 \pm, 53$ & 1,30 & 2,40 & $2,00 \pm, 40$ \\
\hline $\begin{array}{l}\text { Laktat Son Test } \\
(\mathrm{mmol} / \mathrm{L})\end{array}$ & 13 & 13,8 & 15,90 & $14,9 \pm, 72$ & 14,40 & 18,40 & $15,7 \pm 1,10$ \\
\hline $\begin{array}{l}\text { Kalp Atım Hizı } \\
\text { (atım/dk) }\end{array}$ & 13 & 185,0 & 192,0 & $188,1 \pm 1,86$ & 188,0 & 198,0 & $191,0 \pm 3,09$ \\
\hline
\end{tabular}


Tablo 2 incelendiğinde, Yo-Yo AT1 testi için katılımcıların 1529,2 ( $\pm 331,5 \mathrm{~m})$ mesafe katettikleri, laktat düzeylerinin test öncesinde $1,91( \pm, 53 \mathrm{mmol} / \mathrm{L})$, test sonunda $14,9( \pm, 72$ $\mathrm{mmol} / \mathrm{L})$ ve $\mathrm{KAH}_{\text {maks }}$ değerlerinin 188,1 $( \pm 1,86 \mathrm{atım} / \mathrm{dk})$ olduğu görülmektedir. Yo-yo AT2 testinde ise kat1lımciların 738,4 $( \pm 154,5$ m) mesafe katettikleri, laktat düzeylerinin test öncesinde $2,00 \quad( \pm, 40 \mathrm{mmol} / \mathrm{L})$, test sonunda $15,7( \pm 1,10 \mathrm{mmol} / \mathrm{L})$ ve $\mathrm{KAH}_{\text {maks }}$ değerlerinin 191,0 ( $\pm 3,09$ atım/ dk $)$ olduğu görülmektedir.

Tablo 3. Katılımcıların Yo-Yo Aralıklı Toparlanma Seviye 1 ve 2 Test Parametrelerinin Karşılaştırılması

\begin{tabular}{|c|c|c|c|c|c|c|c|}
\hline Değişkenler & & $\mathbf{n}$ & Ortalama & SS & sd & $\mathbf{t}$ & $\mathbf{p}$ \\
\hline \multirow{2}{*}{ Koşu Mesafesi } & AT1 & 13 & 1529,2 & 331,5 & 12 & 14,296 &, $000 * *$ \\
\hline & AT2 & 13 & 738,4 & 154,5 & & & \\
\hline \multirow[t]{2}{*}{0 Dakika } & AT1 & 13 & 188,1 & 1,86 & 12 & $-3,421$ &, $005 *$ \\
\hline & AT2 & 13 & 191,1 & 3,02 & & & \\
\hline \multirow[t]{2}{*}{1 Dakika } & AT1 & 13 & 145,4 & 4,44 & 12 & $-1,182$ & ,260 \\
\hline & AT2 & 13 & 147,7 & 6,30 & & & \\
\hline \multirow[t]{2}{*}{3 Dakika } & AT1 & 13 & 123,7 & 5,84 & 12 & $-2,978$ &, $012 *$ \\
\hline & AT2 & 13 & 130,7 & 8,10 & & & \\
\hline \multirow[t]{2}{*}{5 Dakika } & AT1 & 13 & 116,3 & 4,99 & 12 & $-1,304$ & ,217 \\
\hline & AT2 & 13 & 118,5 & 5,88 & & & \\
\hline \multirow[t]{2}{*}{7 Dakika } & AT1 & 13 & 111,9 & 5,52 & 12 & ,867 & ,403 \\
\hline & AT2 & 13 & 110,6 & 3,03 & & & \\
\hline \multirow[t]{2}{*}{9 Dakika } & AT1 & 13 & 106,6 & 1,98 & 12 &,- 595 & ,563 \\
\hline & AT2 & 13 & 107,0 & 2,58 & & & \\
\hline \multirow[t]{2}{*}{ Test Öncesi Laktat } & AT1 & 13 & 1,91 &, 53 & 12 & $-1,332$ & ,208 \\
\hline & AT2 & 13 & 2,00 & ,40 & & & \\
\hline \multirow[t]{2}{*}{ Test Sonu Laktat } & AT1 & 13 & 14,9 &, 72 & 12 & $-2,056$ & ,062 \\
\hline & AT2 & 13 & 15,7 & 1,10 & & & \\
\hline \multirow[t]{2}{*}{ Maksimal Kalp Atım Hızı } & AT1 & 13 & 188,1 & 1,86 & 12 & $-3,421$ &, $005 *$ \\
\hline & AT2 & 13 & 191,1 & 3,02 & & & \\
\hline
\end{tabular}

$* \mathrm{p}<, 05$

$* * \mathrm{p}<, 001$

Tablo 3 incelendiğinde, Yo-Yo AT1 ve Yo-Yo AT2 testlerinde katedilen toplam mesafe (siraya göre 1529,2 $\pm 331,5 \mathrm{~m} ; 738,4$ $\pm 154,5 \mathrm{~m}, \mathrm{p}<, 001)$ ve $\mathrm{KAH}_{\text {maks }}$ değerleri (sıraya göre 188,1 $\pm 1,86 \mathrm{atım} / \mathrm{dk} ; 191,0 \pm$ 3,09 atım/dk, $\mathrm{p}<, 005)$ bakımından testler arasında istatistiksel olarak anlamlı bir farklılık olduğu görülmektedir. Katılımcılar, Yo-Yo AT2 testinde daha düşük bir mesafe kat etmelerine rağmen, daha yüksek $\mathrm{KAH}_{\text {maks }}$ değerlerine sahiptir. Buna karşılık, hem YoYo AT1 hem de Yo-Yo AT2 testlerinde elde edilen test öncesi $(1,91 \pm, 53 \mathrm{mmol} / \mathrm{L} ; 2,00 \pm$ ,40 mmol/L, siraya göre) ve test sonrası $(14,9$ , $\pm 72 \mathrm{mmol} / \mathrm{L} ; 15,7 \pm 1,10 \mathrm{mmol} / \mathrm{L}$, siraya göre) laktat değerleri bakımından istatistiksel olarak anlamlı bir farklılık yoktur ( $\mathrm{p}>0.005)$.

Tablo 4. Sporcuların Yo-Yo AT1 ile Yo-Yo AT2 Arasındaki Mesafe İlişkisi

\begin{tabular}{lll} 
& \multicolumn{3}{c}{ Yo-Yo AT1 } & \\
& r & p \\
\hline Yo-Yo AT2 & 0.923 & 0.001
\end{tabular}

Tablo 4' de sporcuların Yo-Yo AT1 ile Yo-Yo AT2 arasindaki mesafe parametresinde pozitif yönde anlamlı bir ilişki saptanmıştır $(\mathrm{r}=0.923, \mathrm{p}=0.001)$.
Günümüzde, sporcuların antrenman durumları ve fiziksel kapasiteleri hakkında bilgi sağlamak için antrenörler tarafından kullanılan birçok test vardır ama bu testlerin spor branşının doğasına uygun olması 
gerekir. Futbol gibi k1sa toparlanma dönemlerine sahip aralıklı spor branşlarında, test sirasında kısa toparlanma dönemleri olan ve aralıklı olarak ifade edilen Yo-Yo AT testlerinin kullanılmasının, performansın belirlenmesi için daha geçerli ve uygun olduğu ileri sürülür. 16,21-23 Oyuncuların performans özelliğinin belirlenmesi, uygulanan antrenman verimliliği ve sporcuların fiziksel durumlarına yönelik antrenörlere yararlı bilgi verir. $\mathrm{Bu}$ nedenle, Yo-Yo aralıklı toparlanma testlerinin sporcuların dönemsel performans değerleri hakkında önemli bilgi vereceğini ve sezon esnasındaki performans değişimleri ortaya çıkarabileceği ifade edilir. ${ }^{18}$

$\mathrm{Bu}$ çalışmada, futbol 1. amatör ligde oynayan futbolcuların hazırlık dönemi esnasındaki Yo-Yo AT testlerindeki koşu performansları değerlendirildi ve AT1 testi için $1529,2 \pm 331,5 \mathrm{~m}$, AT2 test için $738,4 \pm 154,5 \mathrm{~m}$ mesafe katettikleri elde edildi. Literatür incelendiğinde, Can ve $\operatorname{arkadaşlari~}^{24}$ tarafindan 3. ligde oynayan futbolcularda yapılan çalışmada, oyuncuların hazırlık döneminde Yo-Yo AT1 testi için ortalama koşu mesafeleri 1539 m olarak elde edilirken, hazırlık dönemi sonundaki koşu mesafeleri ise $1899 \mathrm{~m}$ olarak elde edilmiştir. Elit Türk futbolcular için $1825 \mathrm{~m}^{25}$, elit Danimarkalı futbolcular için $1793 \mathrm{~m}^{18}$, elit Tunuslu futbolcular için $2289 \mathrm{~m}^{26}$, İspanyol elit futbol oyuncuları için $2414 \mathrm{~m}$, amatör futbolcular için ise $2092 \mathrm{~m}^{27}$ ve $2034 \mathrm{~m}^{28}$ ortalama Yo-Yo AT1 koşu mesafesi elde edilmiştir. Ayrıca, Castagna ve arkadaşları tarafindan amatör futbol oyuncularının YoYo AT1 ve Yo-Yo AT2 performanslar1 üzerine yapılan bir çalışmada, oyuncuların koşu mesafeleri söylenen siraya göre $2138 \mathrm{~m}$ ve $1331 \mathrm{~m}$ olarak elde edilmiştir. ${ }^{2} \mathrm{Bu}$ sonuçlar, şimdiki çalışmada elde edilen sonuçlardan oldukça yüksektir. Bu farklılığın, mücadele seviyesinden ve sporcular arasındaki bireysel farklılıklardan kaynaklandığı düşünülür.

Farklı lig seviyelerindeki futbolcuların Yo-Yo AT testlerindeki performanslarına bakıldığında aynı yaş grubundaki elit ve elit olmayan iki takım üzerinde Ueda ve arkadaşları $^{29}$ tarafindan yapılan bir çalışmada, elit futbol oyuncularının ortalama Yo-Yo AT1 koşu mesafeleri 2369 m olarak elde edilirken, elit olmayan takımın ise 2315 $\mathrm{m}$ koşu mesafesi sergilediği elde edildi. Buna karşılık, oyuncuların Yo-Yo AT2 testindeki performansları söylenen sıraya göre $1035 \mathrm{~m}$ ve 919 m olarak elde edilmiştir. Bahsi geçen çalışmada, iki takım arasındaki Yo-Yo AT1 testi bakımından anlamlı bir farklılık elde edilmezken, Yo-Yo AT2 testinde anlamlı bir farklılık bulunmuştur. Buna karşılık Rampinini ve arkadaşları ${ }^{30}$ tarafından yapılan farklı bir çalışmada, hem Yo-Yo AT1 hem de Yo-Yo AT2 testi bakımından amatör (1827 $613 \mathrm{~m})$ ve elit $(2231-958 \mathrm{~m})$ futbolcuların koşu mesafeleri arasında anlamlı bir farklılık gösterilmiştir. Ingebrigtsen ve arkadaşlari ${ }^{22}$ tarafından Norveçli elit ve daha alt düzeydeki bir futbol takımında yapılan çalışmada, elit futbolcuların Yo-Yo AT1 ve Yo-Yo AT2 koşu mesafeleri $2033 \mathrm{~m}$ ve $747 \mathrm{~m}$, daha alt düzeydeki oyuncuların koşu mesafeleri 1633 $\mathrm{m}$ ve $571 \mathrm{~m}$ olarak elde edilmiştir. Veale ve arkadaşları $^{31}$ tarafından aynı yaş grubundaki elit ve daha alt düzeydeki Avustralya takımlarında yapılan bir çalışmada, ortalama Yo-Yo AT1 koşu mesafeleri elit takım için 1910 m, diğer takım için 1438 m olarak elde edilmiştir. Benzer bir çalışma, Rostgaard ve arkadaşları $^{32}$ tarafindan Danimarkalı futbolcularda yapılmıştır. Bahsi geçen çalışmada, elit ve daha alt düzeydeki genç futbolcuların Yo-Yo AT2 testindeki koşu mesafeleri ise $1023 \mathrm{~m}$ ve $893 \mathrm{~m}$ olarak elde edilmiştir. Ayrıca, Teplan ve arkadaşlari ${ }^{33}$ tarafindan U17 Çek Cumhuriyeti U17 milli takımı ile U17 kategorisindeki en iyi ve en kötü takımdaki futbolcuların Yo-Yo AT1 koşu mesafelerinin karşılaştırıldı ğ çalışmada, U17 ulusal takımı oyuncularının Yo-Yo AT1 ortalama koşu mesafeleri 1940 m olarak elde edilirken, U17 kategorisindeki en iyi ve en kötü takımın koşu mesafeleri sıraya göre $1952.2 \mathrm{~m}$ ve $1488.5 \mathrm{~m}$ olarak elde edilmiştir.

$\mathrm{Bu}$ çalışmada, katılımcıların Yo-Yo AT1 testi için test öncesi laktat düzeylerinin $1,91 \pm, 53(\mathrm{mmol} / \mathrm{L})$, test sonunda $14,9 \pm, 72$ (mmol/L) ve ayrica test sonu maksimal kalp

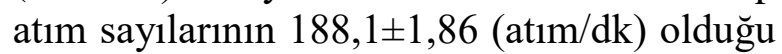


elde edilirken; Yo-Yo AT2 testi için test

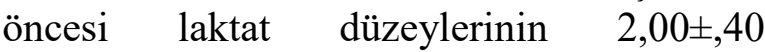
$(\mathrm{mmol} / \mathrm{L})$, test sonunda 15,7 $\pm 1,10(\mathrm{mmol} / \mathrm{L})$ ve test sonu maksimal kalp atım sayılarının

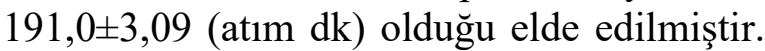
Ingebrigtsen ve arkadaşları ${ }^{22}$ tarafından Norveçli elit ve daha alt düzeydeki bir futbol takımında yapılan çalışmada, elit futbolcuların Yo-Yo AT2 testindeki maksimal kalp atım sayısı değerleri 181.5 atım/dk, daha alt düzeydeki elit futbolcularda $192.6 \mathrm{atım} / \mathrm{dk}$ olarak elde edilmiştir. Aynı çalışmada, Yo-Yo AT1 testi için elit ve daha alt düzeydeki elit futbolcuların ortalama $\mathrm{KAH}_{\text {maks }}$ değerleri söylenen siraya göre 183.7 ve $192.5 \mathrm{atım} / \mathrm{dk}$ olarak elde edilmiştir. Rampinini ve arkadaşlari $^{30}$ tarafından profesyonel ve amatör futbolcularda yapılan çalışmada, profesyonel futbolcularda Yo-Yo AT1 testindeki ortalama $\mathrm{KAH}_{\text {maks }}$ değerleri 188 atım/dk, amatör futbolcularda 191 atım/dk olarak elde edilmiștir. Yo-Yo AT2 testinde ise her iki grubun da ortalama $\mathrm{KAH}_{\text {maks }}$ değerleri $189 \mathrm{atım} / \mathrm{dk}$ olarak elde edilmiştir. Seyis ve ark., ${ }^{34}$, profesyonel Türk futbolcuların Yo-Yo AT1 testinde ortalama $\mathrm{KAH}_{\text {maks }}$ değerini hazırlık döneminde 188 atım/dk, müsabaka sezonu öncesinde 184 atım/dk olarak elde etmişlerdir. Teplan ve ark., ${ }^{33}$ tarafindan U17 kategorisinde mücadele eden futbolcularda yapılan bir çalışmada, Yo-Yo AT1 testindeki ortalama $\mathrm{KAH}_{\text {maks }}$ değerleri U17 Çek Cumhuriyeti ulusal takımı için $197.2 \mathrm{atım} / \mathrm{dk}$, U17 liginin en iyi takımı için $195.2 \mathrm{atım} / \mathrm{dk}$, en kötü takımı için 194 atım/dk olarak elde edilmiştir. Sonuç olarak KAH antrenman protokolünde gerekli çalışma yoğunluğunu takip edebilmek için kullanılır ${ }^{35}$ ve kan dolaşımı için bilgi sağlar. ${ }^{36}$ Ayrıca, Yo-Yo AT testlerinde kalp hızındaki aşamalı artış veya $\mathrm{KAH}_{\text {maks }}$ değerine ulaşmak farklılık gösterebilir. ${ }^{37} \mathrm{Bu}$ sonuçlara göre, antrenmanlı ve profesyonel futbol oyuncularının test sonunda daha düşük kalp atım hızına sahip oldukları ve daha düşük bir kalp atım hızında daha fazla mesafe katettikleri ileri sürülebilir.

Krustrup ve arkadaşları $^{18}$ tarafindan yapılan bir çalışmada, Yo-Yo AT1 testinden önce futbolcuların ortalama KAH değerleri $83 \mathrm{atım} / \mathrm{dk}$ olarak ölçülmüş, testin $440 \mathrm{~m}$, $1080 \mathrm{~m}$ ve 1720 metrelik koşu döneminden sonraki ortalama KAH değerleri söylenen sıraya göre 158,172 ve 181 atım/dk olarak elde edilmiştir. Ayrıca, test öncesi 1.0 mmol.L olarak ölçülen kan laktat konsantrasyonu test sonunda 10.1 mmol.L olarak elde edilmiştir. Test esnasında ulaşılan ortalama $\mathrm{KAH}_{\text {maks }}$ değeri 187 atım/dk olarak elde edilmiştir. Krustrup ve arkadaşları ${ }^{5}$ tarafından yapılan bir başka çalışmada, YoYo AT2 testinden önce futbolcuların ortalama KAH değerleri 109 atım/dk olarak ölçülürken, testin ilk $80 \mathrm{~m}, 160 \mathrm{~m}$ ve 280 metrelik bölümlerinde sporcuların $\mathrm{KAH}$ değerlerinin artarak söylenen siraya göre 157, 176 ve $184 \mathrm{atım} / \mathrm{dk}$ olduğu belirlenmiștir. Test sonunda ise sporcuların ortalama $\mathrm{KAH}_{\text {maks }}$ değerleri $191 \mathrm{atım} / \mathrm{dk}$ olarak belirlenmiştir. Bahsi geçen çalışmada, kan laktat değerleri test öncesi 2.4 mmol.L olarak ölçülürken, $280 \mathrm{~m}$ sonra $5.1 \mathrm{mmol}$.L ve test sonunda $11.5 \mathrm{mmol}$.L olarak elde edilmiştir. İlgili çalışmada Yo-Yo AT1 testindeki kan laktat birikim oranı elit oyunculara göre amatör oyuncularda daha fazladir. Ayrica, Yo-Yo AT1 ile karşılaştırıldığında AT2 testinde kan laktat birikim oranı daha fazladır ve profesyonel oyuncular ile amatör oyuncular arasındaki farklılık daha yüksektir. ${ }^{30}$ Sonuç olarak, yüksek aerobik kapasiteye sahip oyuncular, enerji temini için gerekli yüksek glikojen depolarına ve toparlanma süresinde bir artışa sahiptirler. Ayrıca aerobik kapasitesi yüksek olan oyuncular glikojen depolarında azalma olmadan ve laktat birikimini geciktirerek çok yüksek yoğunlukta ve daha uzun mesafe koşabilir. ${ }^{9}$ 


\section{SONUÇ VE ÖNERILLER}

Sonuç olarak, Yo-Yo AT1 ve Yo-Yo AT2 testleri karșılaștırıldığında katılımcıların YoYo AT1 testinde daha fazla mesafe katettiği görülür. Bu farklılık, Yo-Yo AT2 testindeki koşu hızının daha fazla olmasından ve bu nedenle sporcuların daha kisa sürede maksimal kalp atım sayılarına ulaşmasından kaynaklanır. Yo-Yo AT1 ve Yo-Yo AT2 testi esnasındaki kalp atım sayılarına bakıldığında, koşu mesafeleri arttıkça kalp atım hızının arttığ1 ve Yo-Yo AT2 testinde daha kısa mesafede maksimal kalp atım sayısına ulaşıldığı görülür. Her iki testin sonrasındaki $0,1,3,5,7$ ve 9 . dakikalarda elde edilen toparlanma kalp atım sayılarına bakıldığında, Yo-Yo AT1 testindeki toparlanma hızının daha Yo-Yo yüksek olduğu görülecektir.
Bunun nedeni, Yo-Yo AT2 testindeki maksimal kalp atım sayısının daha fazla olması ve yüksek bir koșu hızında testin yapılmasından dolayı, toparlanma süresinin daha uzun olmasından kaynaklandığı ileri sürülebilir. Testlerin sonundaki kan laktat değerleri arasında istatistiksel olarak anlamlı bir farkl11ık olmamasına rağmen, Yo-Yo AT2 testi sonundaki kan laktat değerlerinin daha yüksek olduğu görülmektedir. Bu sonuç, YoYo AT2 testinde daha düşük bir mesafe katedilmesine rağmen, koșu hızının fazla olmasindan dolayı testin daha fazla yorgunluğa neden olduğunu gösterir.

\section{KAYNAKLAR}

1. Helgerud, J, Engen, C.L, Wisloff, U. and Hoff, J. (2001). "Aerobik Endurance Training Improves Socce Performance". Medicine Science in Sports Exercise, 33 (11), 1925-1931

2. Castagna, C, Impellizzeri, F.M, Chamari, K, Carlomango, D. and Rampinini, E. (2006). "Aerobik Fitness and Yo-Yo Continuous and Intermittent Tests Performances in Soccer Players: A Correlation Study". Journal of Strength and Conditioning Research, 20 (2), $320-325$.

3. Reilly, T, Bangsbo, J. and Franks, A. (2000) "Anthropometric and Physiological Predispositions for Elite Soccer" Journal of Sport Sciences, 18 (9), 669683

4. Andersen, J.L. (2006). "Planning of Strength Training in Soccer Players: Considerations and Important Aspects". In 5th International Conference on Strength Training.

5. Krustrup, P., Mohr, M., Nybo, L., Jensen, J.M., Nielsen, J.J. and Bangsbo, J. (2006). "The Yo-Yo IR2 Test: Physiological Response, Reliability, and Application to Elite Soccer" Medicine Sciences in Sports Exercise, 38(9), 1666-1673

6. Arı, E. ve Deliceoğlu, G. (2021). "The prediction of repeated sprint and speed endurance performance by parameters of critical velocity models in soccer'. Pedagogy of Physical Culture and Sports, 25 (2), 132-143.

7. Stolen, T, Chamari, K, Castagna, C. and Wisloff, U. (2005). "Physiology of Soccer: An Update". Sports Medicine, 35 (6), 501-536.

8. Bangsbo, J. (1994). "The Physiology of Soccer with Special Reference to Intense Intermittent Exercise", Acta Physiologica Scandinavica, 1-155.

9. Hoff, J. (2005). "Training and Testing Physical Capasities for Elite Football Players", Journal of Sports Sciences, 23(6), 573-582.

10. Da Silva, D.C, Bloomfield, J., and Marins, B.C.J. (2008) "A Review of Stature, Body Mass and Maximal Oxygen
Uptake Profiles of U17, U20 and First Division Players in Brazilian Soccer". Journal of Sports Science and Medicine, 7 (3), 309-319.

11. Bravo, D.F, Impellizzeri, M.F, Castagna, C, Bishop, D and Wisloff, U. (2007). "Sprint vs. Interval Training in Football'. International Journal of Sports Medicine, 29 (8), 668-674

12. Çoruh, E. ve Müniroğlu, S. (1998). “Ankara'daki Profesyonel Futbol Takımlarının 14-16 yas Grubu Oyuncularının Somatotip Özellikleri Üzerine Bir İnceleme'. Futbol, Bilim ve Teknoloji Dergisi, 4, 13140 ,

13. Eniseler, N. (2010). Bilimin Ișı̆ğında Futbol Antrenmanı. İzmir. Birleşik Matbaacılık.

14. Sproule, J, Kunalan, C, McNeill, M. and Wright, $\mathrm{H}$. (1993). "Validity of 20-MST for Predicting $\mathrm{VO}_{2 \max }$ of Adult Singaporean Athletes". British Journal of Sports Medicine, 27 (3), 202-204.

15. Bangsbo, J, Laia, F.M. and Krustrup, P. (2008). “The Yo-Yo Intermittent Recovery Test: A Useful Tool for Evaluation of Physical Performance in Intermittent Sport'. Sports Medicine, 38 (1), 37-51.

16. Aziz, R.A, Tan, C. K. and Teh, C.K. (2005). "A Pilot Study Comparing Two Field Tests with the Treadmill Run Test in Soccer Players". Journal of Sports Science and Medicine, 4 (2), 105-112.

17. Bangsbo, J, Mohr, M. and Krustrup, P. (2006). "Physical and Metabolic Demands of Training and Match-Play in the Elite Football Player', Journal of Sports Science, 24 (7), 665-674

18. Krustrup, $\mathrm{P}$, Mohr, $\mathrm{M}$, Amstrup, $\mathrm{T}$, Rysgaard $\mathrm{T}$, Johansen J, Steensberg A, Pedersen, P.K. and Bangsbo, J. (2003). "The Yo-Yo Intermittent Recovery Test: Physiological Response, Reliability, and Validity". Medicine Sciences in Sports Exercise, 35 (4), 697-705.

19. Bayrakdaroğlu, S, Arı, E, Özkamçı, H. ve Can, İ. (2020). 'The examination of Yo-Yo intermittent recovery test performance of young soccer players at different playing 
positions"'. Physical education of students. 24 (4), 235 41.

20. Fess, E. and Moran C. (1981). 'Clinical Assessment Recommendations', Indianapolis: American Society of Hand Therapists, 1-24

21. Sirotic, A.C. and Coutts A.J. (2007). "Physiological and Performance Test Correlates of Prolonged, HighIntensity, Intermittent Running Performance in Moderately Trained Women Team Sport Athletes", Journal of Strength and Conditioning Research, 21(1); 138-144.

22. Ingebrigtsen, J, Bendiksen, M, Randers, M.B, Castagna C, Krustrup, P. and Holtermann, A. (2012). 'YYo-Yo IR Testing of Elite and Sub-Elite Soccer Players: Performance, Heart Rate Response and Correlations to Other Interval Tests", Journal of Sports Science, 30 (13), 1337-1345

23. Can, I, Cihan, H. (2013). "Yo-Yo Aralıklı Toparlanma Testleri ve Sportif Performans Üzerine Genel Bir Değerlendirme'’. Spormetre, 11 (2), 81-94.

24. Can, I, Cihan, H, İmamoğlu, R, Albayrak, A.Y. ve Arı. E. (2013). 'Changes in the Athletic Performances of Soccer Players From Pre and Post Training". 4 International Conference on Sport and Exercise Science, Bangkonk-Tailand.

25. Cihan, H, Can, İ, Seyis, M. ve Arı, E. (2011). 'Profesyonel Erkek Futbolcuların Aerobik Kapasite ve Toparlanma Sürelerinin Belirlenmesi',. 1. Uluslararas Fiziksel Aktivite Beslenme ve Sağlık Kongresi Kitabı. 173-174.

26. Chaouachi, A, Manzi, V, Wong, D.P, Chaalali, A, Laurencelle, L, Chamari, K. and Castagna, C. (2010). 'Intermittent Endurance and Repeated Sprint Ability in Soccer Players"'. Journal of Strength and Conditioning Research, 24 (10); 2663-2669.

27. Mujika, I, Santisteban, J, Impellizzeri, F.M. and Castagna. C. (2009). 'Fitness Determinants of Success in Men's and Women's Football'. Journal of Sports Science, 27 (2), 107-114.

28. Dupont, G, Defontaine, $\mathrm{M}$, Bosquet, L, Blondel, $\mathrm{N}$, Moalla, W. and Berthoin, S. (2009). "Yo-Yo Intermittent Recovery Test Versus The Université de Montréal Track Test Relation with A High-intensity Intermittent Exercise', Journal of Science and Medicine in Sport, 13(1), 146-150

29. Ueda, S, Yamanaka, A, Yoshikawa, T, Katsura, Y, Usui, T, Orita, K. and Fujimoto, S. (2011). 'Differences in Physiological Characterization Between Yo-Yo Intermittent Recovery Test Level 1 and Level 2 in Japanese College Soccer Players', International Journal of Sport and Health Science, 9, 33-38.

30. Rampinini, E, Sassi, A, Azzalin, A, Castagna, C, Menaspa, P, Carlomango, D. and Impellizerri, F.M. (2010). 'Physiological Determinations of Yo-Yo Intermittent Recovery Test in Male Soccer Players", European Journal of Applied Physiology, 108 (2), 401409.

31. Veale, J.P, Pearce, A.J. and Carlson, J.S. (2010). 'The YoYo Intermittent Recovery Test (Level 1) to Discriminate Elite Junior Avustralian Football Players". Journal of Science and Medicine in Sport, 13 (3), 329331.

32. Rostgaard, T, Iaia, F.M, Simonsen, D.S. and Bangsbo, J. (2008). "'A Test to Evaluation the Physical Impact on
Technical Performance in Soccer', Journal of Strenght and Conditioning Research, 21 (1), 283-292.

33. Teplan, J, Maly, T, Zahalka, F, Hrasky, P, Mala, L. and Heller, J. (2012). 'The Level and Differences of Aerobic Capacity in Three Different Young Soccer Team in the U17 Category',. Sport

34. Seyis, M, Cihan, H. ve Can, İ. (2011). 'Elit Futbolcuların Hazırlı Periyodu ve Müsabaka Sezonu Esnasındaki Aerobik Kapasite ve Toparlanma Sürelerinin Oyun Pozisyonlarına Göre Karşılaştırılması', Atatürk Üniversitesi Beden Eğitimi ve Spor Bilimleri Dergisi, 13 (4), 24-38.

35. Svensson, M. and Drust, B. (2005). ''Testing Soccer Players'. Journal of Sports Sciences, 23 (6), 601-618.

36. Ali, A. and Farrally, M. (1991). "'Recording Soccer Player's Heart Rates During Matches',. Journal of Sports Science, 9 (2), 183-189.

37. Walker, S. and Turner, A. (2009). "A One-Day Field Test Battery for the Assessment of Aerobic Capacity". Anaerobic Capacity, Speed and Agility of Soccer Players, Strength and Conditioning Journal, 31 (6), 5260 